\title{
Rectal Foam Dosage Form
}

National Cancer Institute

\section{Source}

National Cancer Institute. Rectal Foam Dosage Form. NCI Thesaurus. Code C91181.

A foam intended for administration to the rectum. 